\title{
Effects of Early-Life Abuse Differ across Development: Infant Social Behavior Deficits Are Followed by Adolescent Depressive-Like Behaviors Mediated by the Amygdala
}

\author{
Charlis Raineki, Millie Rincón Cortés, Laure Belnoue, and Regina M. Sullivan \\ Emotional Brain Institute, Nathan Kline Institute, Child Study Center, Child and Adolescent Psychiatry, New York University School of Medicine, \\ Orangeburg, New York 10962
}

\begin{abstract}
Abuse during early life, especially from the caregiver, increases vulnerability to develop later-life psychopathologies such as depression. Although signs of depression are typically not expressed until later life, signs of dysfunctional social behavior have been found earlier. How infant abuse alters the trajectory of brain development to produce pathways to pathology is not completely understood. Here we address this question using two different but complementary rat models of early-life abuse from postnatal day 8 (P8) to P12: a naturalistic paradigm, where the mother is provided with insufficient bedding for nest building; and a more controlled paradigm, where infants undergo olfactory classical conditioning. Amygdala neural assessment (c-Fos), as well as social behavior and forced swim tests were performed at preweaning (P20) and adolescence (P45). Our results show that both models of early-life abuse induce deficits in social behavior, even during the preweaning period; however, depressive-like behaviors were observed only during adolescence. Adolescent depressive-like behavior corresponds with an increase in amygdala neural activity in response to forced swim test. A causal relationship between the amygdala and depressive-like behavior was suggested through amygdala temporary deactivation (muscimol infusions), which rescued the depressive-like behavior in the forced swim test. Our results indicate that social behavior deficits in infancy could serve as an early marker for later psychopathology. Moreover, the implication of the amygdala in the ontogeny of depressive-like behaviors in infant abused animals is an important step toward understanding the underlying mechanisms of later-life mental disease associated with early-life abuse.
\end{abstract}

\section{Introduction}

Clinical and basic research converge to demonstrate that earlylife adverse experiences such as abuse or maltreatment significantly increase predisposition to psychopathologies, including depression (Sánchez et al., 2001; Connor et al., 2003; Gunnar, 2003; Pollak, 2003; Teicher et al., 2003; Zeanah et al., 2003; Cicchetti and Toth, 2005; Stovall-McClough and Cloitre, 2006; McEwen, 2008; Cirulli et al., 2009; Heim et al., 2009). However, the onset of most psychopathologies does not occur until later in life, generally around adolescence (Costello et al., 2002; Andersen and Teicher, 2008; Paus et al., 2008; Zahn-Waxler et al., 2008). Moreover, clinical research shows that later-life depression is usually associated with childhood social behavior dysfunction

Received Nov. 22, 2011; revised Feb. 21, 2012; accepted Feb. 24, 2012.

Author contributions: C.R. and R.M.S. designed research; C.R., M.R.C., and L.B. performed research; C.R. and R.M.S. analyzed data; C.R. and R.M.S. wrote the paper.

This research was funded by NIH-NIMH Grant MH091451 and NIH Grant DC009910 to R.M.S.; National Science Foundation Graduate Research Fellowship DGE-1137475 to M.R.C.; and CAPES Postdoctoral Fellowship from Brazil to C.R.

All authors have no financial disclosures and/or conflicts of interest to disclose.

Correspondence should be addressed to either Dr. Charlis Raineki or Dr. Regina M. Sullivan, Emotional Brain Institute, Nathan Kline Institute for Psychiatric Research, Child and Adolescent Psychiatry, New York University School of Medicine, 140 Old Orangeburg Road, Orangeburg, NY 10962. E-mail: craineki@mail.ubc.ca or regina.sullivan@nyumc.org.

DOI:10.1523/JNEUROSCI.5843-11.2012

Copyright $\odot 2012$ the authors $\quad 0270-6474 / 12 / 327758-08 \$ 15.00 / 0$
(Mason et al., 2004; Letcher et al., 2009; Mazza et al., 2009). Overall, the literature suggests that the effects of early-life adversities are enduring, although expressed as social behavior deficits early on with a larger spectrum of psychopathology emerging as the organism matures.

In humans, the amygdala is implicated in both depression (Teicher et al., 2002; Bremner, 2003; McEwen, 2003; Ressler and Mayberg, 2007; Savitz and Drevets, 2009; Sibille et al., 2009) and social behavior deficits (Adolphs et al., 1998; Baron-Cohen et al., 1999; Bachevalier, 2000; Howard et al., 2000; Amaral et al., 2003; Haas et al., 2009; Paul et al., 2009). Additionally, clinical research identifies abnormal amygdala function with social behavior deficits and later-life depressive-like behaviors in abusive attachment (Heim and Nemeroff, 1999; Teicher et al., 2002, 2003). These clinical results have been replicated in animals through early-life adversity research also showing amygdala dysfunction with depressive-like behavior and social behavior deficits (Huang and Lin, 2006; Sabatini et al., 2007; Kuramochi and Nakamura, 2009; Sevelinges et al., 2011).

Here, we use two different but complementary rodent models of early-life abuse to examine the amygdala's role in the ontogeny of depressive-like behavior. The first is a naturally abusive paradigm where the mother handles her pups roughly when provided with insufficient bedding for nest building (Roth and Sullivan, 2005; Ivy et al., 2010; Raineki et al., 2010). The second model uses an infant olfactory classical conditioning paradigm where odor- 
Table 1. Frequency of maternal and pup behaviors observed during mother-infant interactions in the abuse rearing infant procedure

\begin{tabular}{llc}
\hline & Abusive mother & Control mother \\
\hline Maternal behaviors & & \\
Step or jump on & $12.78 \%$ & $3.75 \%$ \\
Rough handling & $17.66 \%$ & $1.67 \%$ \\
Nest building & $13.14 \%$ & $0.00 \%$ \\
Nursing & $45.18 \%$ & $73.75 \%$ \\
Mother's time in the nest & $48.69 \%$ & $74.44 \%$ \\
Pups vocalization & $13.97 \%$ & $0.00 \%$ \\
\hline
\end{tabular}

Values are the percentage of observation periods in which behaviors occurred.

shock pairings produce an odor with the same value as the natural maternal odor (Raineki et al., 2010). The deaf and blind pup uses the natural and experimentally learned maternal odors for approach, social behavior, and nipple attachment, and these odors produce a robust olfactory bulb response (for review, see Sullivan and Holman, 2010). In both models, early social behavior appears to be spared during the first days of life, although stress uncovers dysfunctional social behaviors with the mother as well as enhanced amygdala activity, suggesting trauma-induced neural changes. By adulthood, however, neurobehavioral dysfunction in the amygdala-dependent fear system emerges (Sevelinges et al., 2007, 2011; Moriceau et al., 2009). Here we document the ontogeny of behavioral changes throughout later infancy and adolescence following these two models of early-life abuse. Similar to findings in the clinical literature, we hypothesize that dysfunctional social behavior during preweaning age [postnatal day 20 (P20)] may serve as an indicator for later adolescent (P45) onset of depressive-like behaviors and amygdala dysregulation.

\section{Materials and Methods}

\section{Subjects}

We used male and female Long-Evans rats born and bred in our colony (originally from Harlan Laboratories). Animals were housed in polypropylene cages $(34 \times 29 \times 17 \mathrm{~cm})$ with an abundant amount of wood shavings for nest building, and kept in a $20 \pm 1^{\circ} \mathrm{C}$ environment with a $12 \mathrm{~h}$ light/dark cycle. Food and water were available ad libitum. The day of birth was considered $\mathrm{P} 0$, and litters were culled to 12 pups ( 6 males and 6 females) on P1. No animal was used in more than one test or age, and all behavioral tests were performed in the beginning of the afternoon. All animal care and experimental procedures were approved by the Institutional Animal Care and Use Committee, which follows the guidelines from the National Institutes of Health.

\section{Infant abuse paradigms}

Abusive mother paradigm. The mother and her pups were housed in a cage with limited (1.2 cm layer) nesting/bedding material from P8 to P12. This limited bedding environment decreased mothers' ability to construct a nest, which resulted in frequent nest building, spending more time away from the nest, rough handling, and stepping on pups. Consequently, pups spent less time nursing and had increased vocalizations (Table 1). This procedure has previously been used in our laboratory (Roth and Sullivan, 2005; Raineki et al., 2010) and is based on the Baram laboratory procedure (Gilles et al., 1996; Avishai-Eliner et al., 2001; Ivy et al., 2010).

Olfactory classical conditioning paradigm. Beginning at P8, pups were fear conditioned daily for 5 consecutive days. Pups were placed in individual $600 \mathrm{ml}$ beakers and were given a $10 \mathrm{~min}$ acclimation period before conditioning to recover from experimental handling. During a conditioning session, pups received 10 pairings of a 30 s peppermint odor with $0.5 \mathrm{~mA}$ hindlimb shock during the last $1 \mathrm{~s}$ of odor, with an intertrial interval of $4 \mathrm{~min}$. The odor (peppermint, McCormick) was delivered by a flow dilution olfactometer ( $2 \mathrm{~L} / \mathrm{min}$ flow rate) at a concentration of 1:10 peppermint vapor. After conditioning, pups were returned to the home cage (Moriceau and Sullivan, 2006; Raineki et al., 2010).
Control group. The mother and her pups were housed in a cage with abundant (5-7 cm layer) nesting/bedding material from P8 to P12, during which time they were not disturbed. This environment permits the mother to build a nest and spend most of her time ( $\sim 75 \%)$ inside the nest caring for pups.

\section{Social behavior test}

Preweaning (P20) and adolescent (P45) social behavior was tested in a two-chamber apparatus $(45.5 \times 30.5 \times 45 \mathrm{~cm})$ built out of black Plexiglas sheets for the sides and a clear Plexiglas bottom to form an open-top box. A black Plexiglas division $(29.5 \times 23 \mathrm{~cm})$ separated the two chambers and a square opening $(8 \times 6 \mathrm{~cm})$ allowed animals to move between chambers. Two metal cubes $(6 \times 6 \times 6 \mathrm{~cm})$ with circular holes $(1 \mathrm{~cm})$ placed $1 \mathrm{~cm}$ apart in each of the four sides and a metal grid with $0.5 \mathrm{~cm}$ openings $0.5 \mathrm{~cm}$ apart on the top were placed in each chamber during an acclimation period of $5 \mathrm{~min}$. At the end of the acclimation period, the rat was removed from the testing chamber and a younger, same-sex animal was placed inside of the metal cube in the social stimulus chamber (right chamber). The testing rat was placed in the chamber without social stimulus (left chamber), and time spent in each chamber and the number of times that the rat crossed from one chamber to another was recorded for $10 \mathrm{~min}$.

\section{Forced swim test}

Preweaning (P20) and adolescent (P45) depressive-like behavior was tested in a cylinder $(30 \times 24 \times 47.5 \mathrm{~cm})$ filled with water $\left(25 \pm 1^{\circ} \mathrm{C}\right.$ and changed for each test) to a depth and size that would prevent both escape and the tail touching the bottom in an age-appropriate manner. The forced swim test was performed in two sessions separated by $24 \mathrm{~h}$. The first session, lasting $15 \mathrm{~min}$, was conducted to habituate the rats to the test situation, thereby providing a stable, high level of immobile behavior during the $5 \mathrm{~min}$ test session $24 \mathrm{~h}$ later (Porsolt et al., 2001). The time the animal spent immobile was recorded. Immobility was considered as passive floating without struggling, slightly hunched but upright position with the head slightly immersed and minor movements necessary to maintain the head above water (Porsolt et al., 2001; Sevelinges et al., 2011). Following the test, animals were dried, placed in a $32^{\circ} \mathrm{C}$ chamber for $15 \mathrm{~min}$, and returned to home cages.

\section{Neural assessment of amygdala after forced swim test}

Ninety minutes following the end of forced swim test, animals were decapitated, and their brains were removed, frozen, and stored in a $-70^{\circ} \mathrm{C}$ freezer. Brains were sectioned in a cryostat $(20 \mu \mathrm{m})$ at $-20^{\circ} \mathrm{C}$. Every fourth section was collected for immunohistochemistry, and every fifth section was collected for cresyl violet staining. c-Fos sections received a $15 \mathrm{~min}$ postfix in $4 \%$ paraformaldehyde/0.1 M phosphate buffer (PB), pH 7.4. Following fixation, the sections were rinsed first in $50 \mathrm{~mm}$ Tris- $\mathrm{HCl}, 150 \mathrm{~mm} \mathrm{NaCl}$ buffer (TBS), pH7.4, and after in TBS plus $0.05 \%$ Tween 20 (TBS-T). To eliminate peroxidase activity, sections were incubated in $1 \% \mathrm{H}_{2} \mathrm{O}_{2}$ and $70 \%$ methanol for $15 \mathrm{~min}$. Following TBS and TBS-T rinses, slides were incubated in a blocking solution containing $2 \%$ normal goat serum (Jackson ImmunoResearch) and 3\% albumin for $2 \mathrm{~h}$. Slides were then treated overnight at $4^{\circ} \mathrm{C}$ with the primary antibody [anti-c-Fos (Ab5) (4-17) Rabbit pAb, Calbiochem] diluted 1:15,000 in blocking solution. Afterward, they were incubated in the secondary antibody (goat anti-rabbit IgG, Jackson ImmunoResearch) diluted 1:500 in $50 \%$ blocking solution for $1 \mathrm{~h}$ at room temperature followed by TBS and TBS-T rinses. Subsequently, the sections were treated for $90 \mathrm{~min}$ in avidin-biotin-peroxidase complex solution (ABC kit, Vector Laboratories). Slides were then rinsed in TBS and TBS-T and treated with a solution containing 3.3'-diaminobenzidine, $\mathrm{H}_{2} \mathrm{O}_{2}$ and nickel (Vector Laboratories), dehydrated in alcohol and xylene, and finally coverslipped for microscope examination.

c-Fos-positive cells were counted bilaterally using a microscope (Olympus) with $10 \times$ objective equipped with a drawing tube. Brain areas were outlined using the corresponding cresyl violet sections according to a stereotaxic rat brain atlas (Paxinos and Watson, 1997). All c-Fospositive cells were distinguished from background by density of staining, shape, and size of cells, and were counted without knowledge of the experimental condition. The mean number of c-Fos cells per brain area 
for an animal was determined by averaging the counts from three sections per brain area. We examined basal, lateral, cortical, medial, and central amygdala nuclei.

\section{Surgery and amygdala infusion before forced swim test}

On P42, rats were anesthetized by isoflurane inhalation and placed in a stereotaxic apparatus. Stainless steel cannulae (30 gauge tubing) were implanted bilaterally in the amygdala through holes drilled in the overlying skull. Stereotaxic coordinates, derived from the atlas by Paxinos and Watson (1997), were used for implanting cannulae into the amygdala (caudal: $2.1 \mathrm{~mm}$ from bregma; lateral: $5.0 \mathrm{~mm}$ from bregma). Cannulae were lowered $6.5 \mathrm{~mm}$ from the surface of the brain, placing the tip near the amygdala and were fixed to the skull with dental cement. To ensure patency of the cannulae, guide wires were placed in the lumen of the tubing until testing. After recovery from surgery (generally within 30 $\mathrm{min}$ ), rats were returned to the home cage for a $3 \mathrm{~d}$ recovery period until testing. On P45, animals received the first day of the forced swim test. On $\mathrm{P} 46$, before the second day of forced swim test, rats' bilateral cannulae were attached via PE10 tubing to a Harvard Apparatus syringe pump driving two Hamilton microliter syringes. The cannulae were filled (16 s at $0.5 \mu \mathrm{l} / \mathrm{min})$ with muscimol $\left(1 \mu \mathrm{g} / \mu \mathrm{l}\right.$ dissolved in $0.9 \%$ saline; $\mathrm{GABA}_{\mathrm{A}}$ receptor agonist, Sigma) or physiological saline (0.9\%). Rats received muscimol or saline infused at $0.1 \mu \mathrm{l} / \mathrm{min}$ for $5 \mathrm{~min}$, for a total infusion volume of $0.5 \mu \mathrm{l}$. After infusion, $1 \mathrm{~min}$ was allowed for diffusion before removing the PE10 tubing. The forced swim test started $15 \mathrm{~min}$ following saline or muscimol infusion.

\section{Verifying cannula placement}

After testing, brains were removed, frozen, sectioned $(20 \mu \mathrm{m})$ in a $-20^{\circ} \mathrm{C}$ cryostat, and cresyl violet stained for identification of the cannula placement in relation to amygdala using an atlas (Paxinos and Watson, 1997).

\section{Statistical analysis}

Data were analyzed by ANOVA followed by post hoc Fisher tests. Correlation between immobility in the forced swim test and c-Fos expression in the amygdala nuclei were assessed by Pearson's $r$ correlation analysis. Differences were considered significant when $p<0.05$.

\section{Results}

\section{Behavior}

Social behavior

Both early-life abuse paradigms (abusive mother and odor-shock conditioning) induce dysfunctional social behavior as early as P20 (Fig. $1 A, B$ ). Our results show that P20 rats that had been raised by an abusive mother or had undergone odor-shock conditioning from P8 to P12 spent significantly less time in the chamber with the social stimulus than control rats $\left(F_{(2,17)}=\right.$ 34.35, $p<0.0001$ ) (Fig. 1A). This dysfunctional social behavior persists until adolescence (P45), where rats that had been raised by an abusive mother or had undergone odor-shock conditioning from P8 to P12 also spent significantly less time in the chamber with the social stimulus than controls $\left(F_{(2,17)}=5.40, p<\right.$ $0.02)$ (Fig. $1 B$ ). No difference was found at P20 $\left(F_{(2,17)}=1.69\right)$ (Fig. $1 C)$ and $\mathrm{P} 45\left(F_{(2,17)}=0.56\right)$ (Fig. $\left.1 D\right)$ in the number of times that the rats that had been raised by an abusive mother or had undergone odor-shock conditioning crossed between the chambers with and without the social stimulus when compared with the control rats, indicating that the reduction of time spent in the chamber with the social stimulus was not due to deficits in locomotion.

\section{Forced swim test}

Our results show that both early-life abuse paradigms did not induce depressive-like behavior in preweaning rats, but both paradigms were able to induce depressive-like behavior during adolescence (P45) (Fig. 2A,B). Specifically, at P20 in a forced swim test, no difference in the time spent immobile was found between
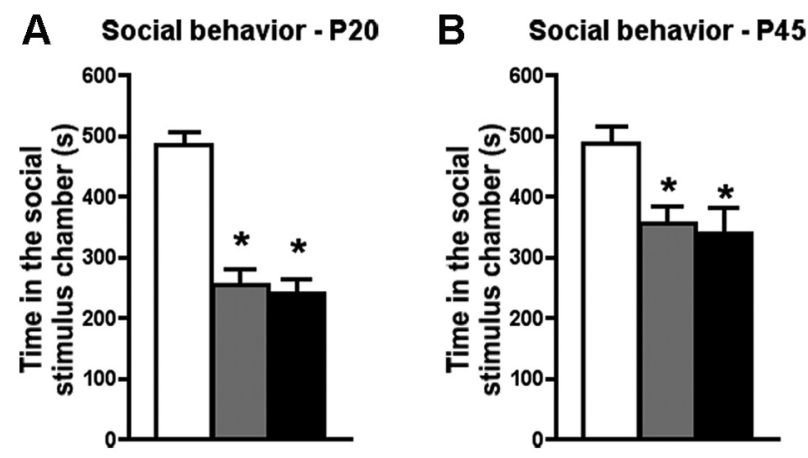

\section{Chamber crossings - P20}
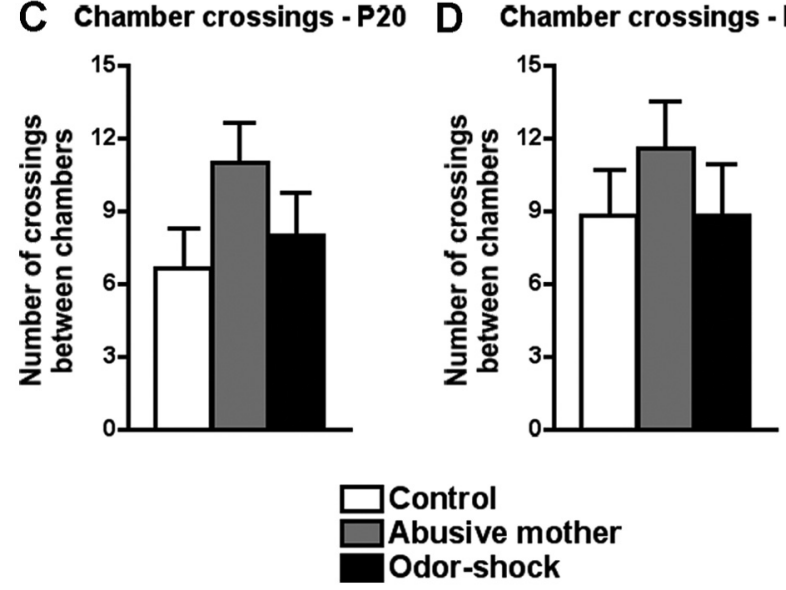

Figure 1. $\quad \boldsymbol{A}, \boldsymbol{B}$, Social interaction test of preweaning (P20; $\boldsymbol{A})$ and adolescent (P45; $B$ ) rats that were abused during early life (reared by a naturally abusive mother or received daily odor-shock conditioning from P8 to P12) and controls. Preweaning and adolescent rats of both abuse paradigms spent significantly less time in the chamber with the social encounter when compared with control rats. $\boldsymbol{C}, \boldsymbol{D}$, Number of crossings between the chambers with and without the social stimulus of preweaning (P20; $C$ ) and adolescent $(P 45 ; \boldsymbol{D})$ rats that were abused during early life. No difference was found between groups at either age. ${ }^{*} p<0.05$, significant difference from each group ( $n=5-7$ for all groups).

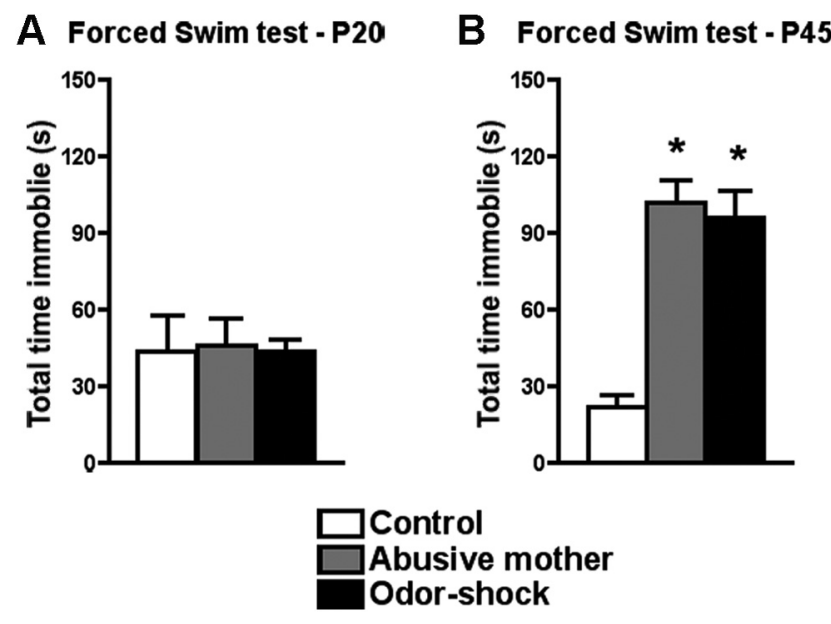

Figure 2. $\quad \boldsymbol{A}, \boldsymbol{B}$, Forced swim test of preweaning $(\mathrm{P} 20 ; \boldsymbol{A})$ and adolescent $(\mathrm{P} 45 ; \boldsymbol{B})$ rats that were abused during early life (reared by a naturally abusive mother or received daily odor-shock conditioning from P8 to P12) and controls. Only adolescent rats reared in both abuse paradigms spent significantly more time immobile when compared with control rats. ${ }^{*} p<0.05$, significant difference from each group ( $n=5-8$ for all groups). 

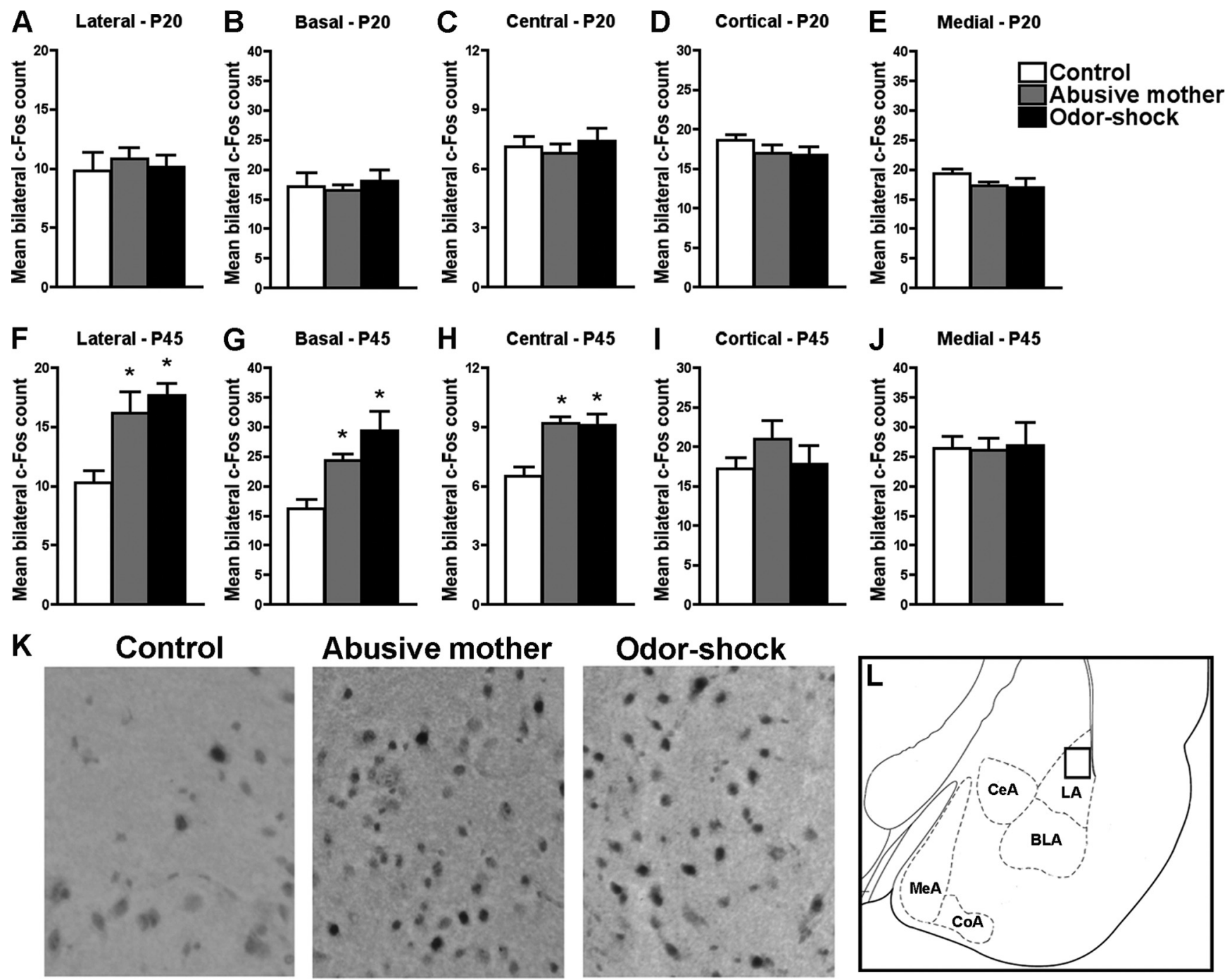

Figure 3. A-J, Amygdala neural activity was assessed with c-Fos immunohistochemistry in response to the forced swim test in preweaning (P20; $\boldsymbol{A}-\boldsymbol{E})$ and adolescent (P45; $\boldsymbol{F}-\boldsymbol{J})$ rats that were abused during early life (reared by a naturally abusive mother or received daily odor-shock conditioning from P8 to P12) and controls. No significant difference in amygdala c-Fos expression was found in preweaning rats. In adolescence, the lateral, basal, and central amygdala nuclei of rats that were abused during infancy exhibited significantly more c-Fos expression when compared with control rats. Bars represent the number (mean \pm SEM) of c-Fos-positive cells counted bilaterally in each amygdala nucleus. ${ }^{*} p<0.05$ between groups ( $n=4-5$ for all groups). $\boldsymbol{K}$, Representative photomicrographs of lateral amygdala from control, abusive mother, and odor-shock groups at P45 displaying c-Fos immunoreactive neurons. $L$, Schematic representation of amygdala nuclei analyzed. BLA, Basal; LA, lateral; (eA, central; MeA, medial; CoA, cortical). The square inside lateral amygdala indicates the approximate position of the representative photomicrographs.

groups $\left(F_{(2,17)}=0.02, p=0.98\right)$ (Fig. $\left.2 A\right)$. However, at P45, rats that had either been raised by an abusive mother or had undergone odor-shock conditioning from P8 to P12 spent significantly more time immobile than controls $\left(F_{(2,18)}=23.20, p<0.0001\right)$ (Fig. 2B).

Amygdala neural assessment in response to forced swim test Using c-Fos immunohistochemistry, assessment of amygdala neural activity in response to forced swim test in rats that received infant odor-shock conditioning or that were raised by an abusive mother revealed that no amygdala nuclei analyzed (lateral, basal, central, medial, and cortical) were activated by forced swim during the preweaning period (P20) (Fig. 3A-E). However, during adolescence (P45) (Fig. 3F-J) both early-life abuse groups (infant odor-shock conditioning or raised by an abusive mother) showed increased c-Fos expression in lateral $\left(F_{(2,11)}=8.23, p<0.01\right)$, basal $\left(F_{(2,11)}=\right.$ 9.17, $p<0.007)$, and central $\left(F_{(2,11)}=10.54, p<0.005\right)$ amygdala nuclei in response to forced swim test compared with controls. Pearson's correlation revealed a positive correlation between time immobile in the forced swim test and c-Fos expression in three amygdala nuclei-lateral $(r=0.46$, $p<0.02)$, central $(r=0.64, p<0.002)$, and basal $(r=0.32$, $p=0.05)$ - only during adolescence. During infancy, no correlation was found between time immobile in the forced swim test and c-Fos expression in any amygdala nuclei.

Temporary inactivation of the amygdala during forced swim test

Temporary deactivation of the amygdala with muscimol (a $\mathrm{GABA}_{\mathrm{A}}$ receptor agonist), during the forced swim test rescued the depressive-like behavior during the forced swim test in adolescent animals (P45) that were raised by an abusive mother (Fig. 4A). A significant interaction between condition and drug infusion was detected $\left(F_{(1,20)}=16.50, p<0.0006\right)$. Post hoc Fisher tests revealed that rats raised by an abusive 

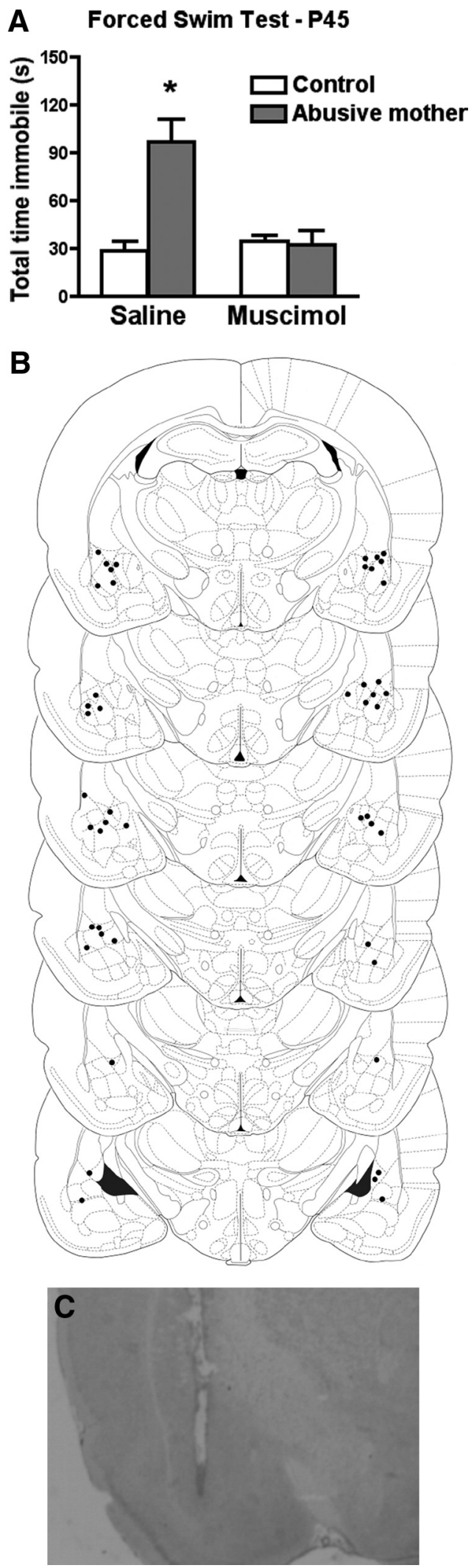

Figure 4. A, Temporary deactivation of the amygdala with muscimol (GABA $A_{A}$ agonist) during the forced swim test rescues the depressive-like behavior in adolescent animals (P45) that were raised by an abusive mother from P8 to P12. ${ }^{*} p<0.05$ between groups ( $n=5-7$ for all groups). $\boldsymbol{B}$, Representative cannula placement in the amygdala for animals receiving either muscimol or saline infusions. Schematic brain section images are displayed from most rostral to most caudal. C, Photomicrograph of representative cannula placement in the amygdala. mother and infused with saline into the amygdala before the forced swim test spent significantly more time immobile than control rats infused with either saline or muscimol. However, rats raised by an abusive mother and infused with muscimol into the amygdala before the forced swim test showed no difference in time spent immobile compared with controls infused with either saline or muscimol.

\section{Discussion}

The present results indicate that both models of early-life abuse (natural abusive mother or odor-shock conditioning) induce similar and dynamic neurobehavioral changes during development. Specifically, social behavior deficits were found just before weaning (P20) and in adolescence (P45), but depressive-like behaviors were seen only during adolescence in both models. Additionally, only the depressive-like behavior during adolescence was associated with increased amygdala activation in central, lateral, and basal nuclei. A causal relationship between the amygdala and the depressive-like behavior was suggested through temporary amygdala deactivation, which rescued the depressive-like behavior, as assessed by the forced swim test.

\section{Ontogeny of early-life abuse deficits: dysfunctional social behavior is followed by depressive-like behavior}

Our results confirm the clinical (Gunnar, 2003; Teicher et al., 2003; Cicchetti and Toth, 2005; Stovall-McClough and Cloitre, 2006; Heim et al., 2009) and animal (Sánchez et al., 2001; Cameron et al., 2005; McEwen, 2008; Cirulli et al., 2009; Sevelinges et al., 2011) literature indicating that early-life abuse constitutes a major risk factor for the development of psychopathologies, including depression. Additionally, our results establish an ontogenetic pattern for the neurobehavioral deficits induced by both early-life abuse models (abusive mother and odor-shock conditioning). Specifically, rats that experienced early-life abuse initially showed only social behavior deficits, but by adolescence also expressed depressive-like behaviors. This delayed manifestation of depressive-like behavior until adolescence is also observed in the clinical population (Costello et al., 2002; Andersen and Teicher, 2008; Paus et al., 2008; Zahn-Waxler et al., 2008; Gogtay et al., 2011). Furthermore, we suggest that these social behavior deficits preceding depressive-like behaviors in rats are comparable to childhood dysfunctional social behavior preceding depressive symptoms during adolescence as described in the clinical literature (Mason et al., 2004; Letcher et al., 2009; Mazza et al., 2009). Finally, depressive-like behaviors observed in adolescence persist into adulthood, as observed through assessment of sucrose consumption and forced swim tests in adult rats receiving odorshock conditioning during infancy (Sevelinges et al., 2011: Sullivan et al., 2011) or being raised by an abusive mother (S. Colcombe, C. Raineki, M. Rincón Cortés, B. Biswal, R. Bisaz, D. Guilfoyle, R. M. Sullivan, and F. X. Castellanos, unpublished observations).

\section{Amygdala's role in the ontogeny of depressive-like behavior of early-life abused rats}

Emotional regulation is a complex function that requires the dynamic interconnection of several brain regions, including the amygdala, hippocampus, and prefrontal cortex (Drevets, 2001; Drevets et al., 2008; Rigucci et al., 2010; Ritchey et al., 2011). Abnormal function of any of these highly interconnected regions has been implicated in depression and antidepressant action (Berton and Nestler, 2006; Krishnan and Nestler, 2008, 2010). Additionally, many patients with depression have been found to have amygdala abnormalities (Teicher et al., 2002; Bremner, 
2003; McEwen, 2003; Ressler and Mayberg, 2007; Savitz and Drevets, 2009; Sibille et al., 2009). Research investigating the effects on children exposed to early-life abuse has demonstrated a stronger link among abnormal amygdala function, social behavior problems, and depressive-like behaviors (Heim and Nemeroff, 1999; Teicher et al., 2002, 2003), which has been modeled in rats (Huang and Lin, 2006; Sabatini et al., 2007; Leussis and Andersen, 2008; Kuramochi and Nakamura, 2009; Sevelinges et al., 2011). Indeed, the amygdala-specifically the basolateral complex-has been defined as a part of the neural circuitry activated with depressive-like symptoms and the forced swim test (Duncan et al., 1993; Huang and Lin, 2006; Coryell et al., 2009). Here, we have been able to demonstrate the relationship of early-life abuse, increased neural activity of the amygdala, and adolescent depressive-like behavior using our two models of early-life abuse. A causal link is suggested by the fact that temporary deactivation of the amygdala with muscimol (a $\mathrm{GABA}_{\mathrm{A}}$ receptor agonist) in adolescent rats with infant abuse was able to reverse depressivelike behaviors as indicated by the normalized performance on the forced swim test.

\section{Advantages of using two early-life abuse paradigms}

By using two different early-life abuse paradigms, we were able to explore the ontogeny of depressive-like behaviors and amygdala dysregulation. The first model is a naturalistic abusive paradigm developed by Baram's laboratory (Gilles et al., 1996; AvishaiEliner et al., 2001; Ivy et al., 2010) and has been used in our laboratory (Roth and Sullivan, 2005; Raineki et al., 2010) to provide ecological validity to the more controlled odor-shock conditioning model. This natural abusive paradigm reflects the complex dynamics of an abusive relationship experienced by children and the particular susceptibility to developing later-life pathology, including depression (Schore, 2001; Gunnar, 2003; Teicher et al., 2003; Cicchetti and Toth, 2005; Stovall-McClough and Cloitre, 2006; Heim et al., 2009). By providing a limited bedding environment, we are able to change the mother's behavior, inducing an abusive phenotype where the mother spends more time trying to build a nest, spends more time away from the nest, handles pups roughly, and steps on pups (Table 1). Consequently, pups spend less time nursing and show increases in vocalizations, although they show normal weight gain (Raineki et al., 2010). As a consequence of being raised in this paradigm, pups exhibit dysfunctional social behavior with the mother during early infancy that is supported by abnormal amygdala activation, although stress (corticosterone) is required to uncover these effects (Raineki et al., 2010). Together, these findings suggest that the quality of the first social relationships during infancy programs the development of emotional and cognitive abilities.

The second model, which involves infant olfactory classical conditioning, provides additional information about specific circuitry activated during infancy to produce the later-life brain and behavior dysfunctions. Specifically, this procedure of pairing a neutral odor with a painful $0.5 \mathrm{~mA}$ shock can capitalize on the well documented neural circuitry in both adult (LeDoux, 1998; Fanselow and LeDoux, 1999; Maren, 2003) and infant rats (Sullivan et al., 2000; Moriceau and Sullivan, 2006; Moriceau et al., 2006; Barr et al., 2009; Raineki et al., 2009), facilitating comprehension and interpretation of experimental results. Another advantage of infant odor-shock conditioning is the fact that the odor paired with shock before P10 uses the same neural pathway the infant rat naturally uses to learn maternal odor, although the amygdala fails to show plasticity (Sullivan et al., 2000; Moriceau and Sullivan, 2006; Raineki et al., 2009). As such, the neutral odor paired with shock acquires the quality/value of the maternal odor, and is able to control mother-pup social behavior (Sullivan et al., 2000; Raineki et al., 2010). Similar to the naturally abusive paradigm, animals that receive odor-shock conditioning also display dysfunctional social behavior with the mother that is supported by abnormal activation of the amygdala when under stress (Raineki et al., 2010).

Importantly, previous research has shown that animals receiving the same number of shocks during infancy, but in an unpredictable manner, later fail to show depressive-like behavior or amygdala dysregulation (Sevelinges et al., 2011), although they do express heightened anxiety (Tyler et al., 2007). Thus, pain during infancy is insufficient to produce the later-life abnormalities observed in the present study.

\section{Implications}

Understanding the ontogeny of the underlying mechanisms of neurobehavioral deficits induced by early-life abuse is a crucial step toward the development of specific strategies for preventing and/or treating resultant psychopathologies in these individuals. Unfortunately, neither clinical nor animal research has completely elucidated these mechanisms. The results presented here expand our knowledge of potential underlying mechanisms by establishing rodent models of well characterized phenomena from the clinical literature and linking the abnormal activation of an important structure such as the amygdala to the negative effects of early-life abuse. Indeed, these models establish an ontogenetic pattern that could be used to study the clinical profile of social behavior deficits that generally precede later-life mental dysfunction.

\section{References}

Adolphs R, Tranel D, Damasio AR (1998) The human amygdala and social judgment. Nature 393:470-474.

Amaral DG, Bauman MD, Schumann CM (2003) The amygdala and autism: implications from non-human primate studies. Genes Brain Behav 2:295-302.

Andersen SL, Teicher MH (2008) Stress, sensitive periods and maturational events in adolescence depression. Trends Neurosci 31:183-191.

Avishai-Eliner S, Gilles EE, Eghbal-Ahmadi M, Bar-El Y, Baram TZ (2001) Altered regulation of gene and protein expression of hypothalamicpituitary-adrenal axis components in an immature rat model of chronic stress. J Neuroendocrinol 13:799-807.

Bachevalier J (2000) The amygdala, social cognition, and autism. In: The amygdala (Aggleton J, ed), pp 509-543. New York: Oxford UP.

Baron-Cohen S, Ring HA, Wheelwright S, Bullmore ET, Brammer MJ, Simmons A, Williams SC (1999) Social intelligence in the normal and autistic brain: an fMRI study. Eur J Neurosci 11:1891-1898.

Barr GA, Moriceau S, Shionoya K, Muzny K, Gao P, Wang S, Sullivan RM (2009) Transitions in infant learning are modulated by dopamine in the amygdala. Nat Neurosci 12:1367-1369.

Berton O, Nestler EJ (2006) New approaches to antidepressant drug discovery: beyond monoamines. Nat Rev Neurosci 7:137-151.

Bremner JD (2003) Long-term effects of childhood abuse on brain and neurobiology. Child Adolesc Psychiatr Clin N Am 12:271-292.

Cameron NM, Champagne FA, Parent C, Fish EW, Ozaki-Kuroda K, Meaney MJ (2005) The programming of individual differences in defensive responses and reproductive strategies in the rat though variations in maternal care. Neurosci Biobehav Rev 29:843-865.

Cicchetti D, Toth SL (2005) Child maltreatment. Annu Rev Clin Psychol $1: 409-438$.

Cirulli F, Francia N, Berry A, Aloe L, Alleva E, Suomi SJ (2009) Early life stress a risk factor for mental health: role of neurotrophins form rodents to non-humans primates. Neurosci Biobehav Rev 33:573-585.

Connor DF, Doerfler LA, Volungis AM, Steingard RJ, Melloni Jr RH (2003) Aggressive behavior in abused children Ann N Y Acad Sci 1008:79-90.

Coryell MW, Wunsch AM, Haenfler JM, Allen JE, Schnizler M, Ziemann AE, Cook MN, Dunning JP, Price MP, Rainier JD, Liu Z, Light AR, Langbehn 
DR, Wemmie JA (2009) Acid-sensing ion channel-1a in the amygdala, a novel therapeutic target in depression-related behavior. J Neurosci 29:5381-5388.

Costello EJ, Pine DS, Hammen C, March JS, Plotsky PM, Weissman MM, Biederman J, Goldsmith HH, Kaufman J, Lewinsohn PM, Hellander M, Hoagwood K, Koretz DS, Nelson CA, Leckman JF (2002) Development and natural history of mood disorders. Biol Psychiatry 52:529-542.

Drevets WC (2001) Neuroimaging and neuropathological studies of depression: implications for the cognitive-emotional features of mood disorders. Curr Opin Neurobiol 11:240-249.

Drevets WC, Price JL, Furey ML (2008) Brain structural and functional abnormalities in mood disorders: implications for neurocircuitry models of depression. Brain Struct Funct 213:93-118.

Duncan GE, Johnson KB, Breese GR (1993) Topographic patterns of brain activity in response to swim stress: assessment by 2-deosyglucose uptake and expression of Fos-like immunoreactivity. J Neurosci 13:3932-3943.

Fanselow MS, LeDoux JE (1999) Why we think plasticity underlying Pavlovian fear conditioning occurs in the basolateral amygdala. Neuron 23:229-232.

Gilles EE, Schultz L, Baram TZ (1996) Abnormal corticosterone regulation in an immature rat model of continuous chronic stress. Pediatr Neurol 15:114-119.

Gogtay N, Vyas NS, Testa R, Wood SJ, Pantelis C (2011) Age of onset of schizophrenia: perspectives from structural neuroimaging studies. Schizophr Bull 37:504-513.

Gunnar MR (2003) Integrating neuroscience and psychological approaches in the study of early experiences. Ann N Y Acad Sci 1008:238-247.

Haas BW, Mills D, Yam A, Hoeft F, Bellugi U, Reiss A (2009) Genetic influences on sociability: heightened amygdala reactivity and event-related responses to positive social stimuli in Williams syndrome. J Neurosci 29:1132-1139.

Heim C, Nemeroff CB (1999) The impact of early adverse experiences on brain systems involved in the pathophysiology of anxiety and affective disorders. Biol Psychiatry 46:1509-1522.

Heim C, Bradley B, Mletzko TC, Deveau TC, Musselman DL, Nemeroff CB, Ressler KJ, Binder EB (2009) Effects of childhood trauma on adult depression and neuroendocrine function: sex-specific moderation by $\mathrm{CRH}$ receptor 1 gene. Front Behav Neurosci 3:41.

Howard MA, Cowell PE, Boucher J, Broks P, Mayes A, Farrant A, Roberts N (2000) Convergent neuroanatomical and behavioural evidence of an amygdala hypothesis of autism. Neuroreport 11:2931-2935.

Huang TY, Lin CH (2006) Role of amygdala MAPK activation on immobility behavior of forced swim test. Behav Brain Res 173:104-111.

Ivy AS, Rex CS, Chen Y, Dubé C, Maras PM, Grigoriadis DE, Gall CM, Lynch G, Baram TZ (2010) Hippocampal dysfunction and cognitive impairments provoked by chronic early-life stress involve excessive activation of CRH receptors. J Neurosci 30:13005-13015.

Krishnan V, Nestler EJ (2008) The molecular neurobiology of depression. Nature 455:894-902.

Krishnan V, Nestler EJ (2010) Linking molecules to mood: new insight into the biology of depression. Am J Psychiatry 167:1305-1320.

Kuramochi M, Nakamura S (2009) Effects of postnatal isolation rearing and antidepressant treatment on the density of serotonergic and noradrenergic axons and depressive behaviors in rats. Neuroscience 163:448 -455.

LeDoux J (1998) Fear and the brain: where have we been, and where are we going? Biol Psychiatry 44:1229-1238.

Letcher P, Smart D, Sanson A, Toumbourou JW (2009) Psychosocial precursors and correlates a differing internalizing trajectories from 3 to 15 years. Soc Dev 18:618-646.

Leussis MP, Andersen SL (2008) Is adolescence a sensitive period for depression? Behavioral and neuroanatomical findings from a social stress model. Synapse 62:22-30.

Maren S (2003) The amygdala, synaptic plasticity, and fear memory. Ann N Y Acad Sci 985:106-113.

Mason WA, Kosterman R, Hawkins JD, Herrenkohl TI, Lengua LJ, McCauley E (2004) Predicting depression, social phobia, and violence in early adulthood form childhood behavior problems. J Am Acad Child Adolesc Psychiatry 43:307-315.

Mazza JJ, Abbott RD, Fleming CB, Harachi TW, Cortes RC, Park J, Haggerty KP, Catalano RF (2009) Early predictors of adolescent depression. J Early Adolesc 29:664-692.
McEwen BS (2003) Early life influences on life-long patterns of behavior and health. Ment Retard Dev Disabil Res Rev 9:149-154.

McEwen BS (2008) Understanding the potency of stressful early life experiences on brain and body function. Metabolism 57:S11-S15.

Moriceau S, Sullivan RM (2006) Maternal presence serves as a switch between learning fear and attraction in infancy. Nat Neurosci 9:1004-1006.

Moriceau S, Wilson DA, Levine S, Sullivan RM (2006) Dual circuitry for odor-shock conditioning during infancy: corticosterone switches between fear and attraction via amygdala. J Neurosci 26:6737-6748.

Moriceau S, Raineki C, Holman JD, Holman JG, Sullivan RM (2009) Enduring neurobehavioral effects of early life trauma mediated through learning and corticosterone suppression. Front Behav Neurosci 3:22.

Paul BM, Snyder AZ, Haist F, Raichle ME, Bellugi U, Stiles J (2009) Amygdala response to faces parallels social behavior in Williams syndrome. Soc Cogn Affect Neurosci 4:278-285.

Paus T, Keshavan M, Giedd JN (2008) Why do many psychiatric disorders emerge during adolescence? Nat Rev Neurosci 9:947-957.

Paxinos G, Watson C (1997) The rat brain in stereotaxic coordinates. New York: Academic.

Pollak SD (2003) Experience-dependent affective learning and risk for psychopathology in children. Ann N Y Acad Sci 1008:102-111.

Porsolt RD, Brossard G, Hautbois C, Roux S (2001) Rodent models of depression: forced swimming and tail suspension behavioral despair tests in rats and mice. In: Current protocols in neuroscience, Vol 2 (Crawley JN, Gerfen CR, Rogawski MA, Sibley DR, Skolnick P, Wray S, eds), unit 8.10A, pp 1-10. New York: Wiley.

Raineki C, Shionoya K, Sander K, Sullivan RM (2009) Ontogeny of odorLiCl vs. odor-shock learning: similar behaviors but divergent ages of functional amygdala emergency. Learn Mem 16:114-121.

Raineki C, Moriceau S, Sullivan RM (2010) Developing a neurobehavioral animal model of infant attachment to an abusive caregiver. Biol Psychiatry 67:1137-1145.

Ressler KJ, Mayberg HS (2007) Targeting abnormal neural circuits in mood and anxiety disorders: from the laboratory to the clinic. Nat Neurosci 10:1116-1124.

Rigucci S, Serafini G, Pompili M, Kotzalidis GD, Tatarelli R (2010) Anatomical and functional correlates in major depressive disorders: the contribution of neuroimaging studies. World J Biol Psychiatry 11:165-180.

Ritchey M, Dolcos F, Eddington KM, Strauman TJ, Cabeza R (2011) Neural correlates of emotional processing in depression: changes with cognitive behavioral therapy and predictors of treatment response. J Psychiatr Res 45:577-587.

Roth TL, Sullivan RM (2005) Memory of early maltreatment: neonatal behavioral and neural correlates of maternal maltreatment within the context of classical conditioning. Biol Psychiatry 57:823-831.

Sabatini MJ, Ebert P, Lewis DA, Levitt P, Cameron JL, Mirnics K (2007) Amygdala gene expression correlated of social behavior in monkeys experiencing maternal separation. J Neurosci 27:3295-3304.

Sánchez MM, Ladd CO, Plotsky PM (2001) Early adverse experience as a developmental risk factor for later psychopathology: evidence from rodent and primate models. Dev Psychopathol 13:419-449.

Savitz J, Drevets WC (2009) Bipolar and major depressive disorder: neuroimaging the developmental-degenerative divide. Neurosci Biobehav Rev 33:699-771.

Schore AN (2001) The effects of early relational trauma on right brain development, affect regulation, and infant mental health. Infant Ment Health J 22:201-269.

Sevelinges Y, Moriceau S, Holman P, Miner C, Muzny K, Gervais R, Mouly AM, Sullivan RM (2007) Enduring effects of infant memories: infant odor-shock conditioning attenuates amygdala activity and adult fear conditioning. Biol Psychiatry 62:1070-1079.

Sevelinges Y, Mouly AM, Raineki C, Moriceau S, Forest C, Sullivan RM (2011) Adult depression-like behavior, amygdala dysfunction and olfactory cortex functions are restored by odor previously paired with shock during infant's sensitive period attachment learning. Dev Cogn Neurosci $1: 77-87$.

Sibille E, Wang Y, Joeyen-Waldorf J, Gaiteri C, Surget A, Oh S, Belzung C, Tseng GC, Lewis DA (2009) A molecular signature of depression in the amygdala. Am J Psychiatry 166:1011-1024.

Stovall-McClough KC, Cloitre M (2006) Unresolved attachment, PTSD, and dissociation in women with childhood abuse histories. J Consult Clin Psychol 74:219-228. 
Sullivan RM, Holman PJ (2010) Transitions in sensitive period attachment learning in infancy: the role of corticosterone. Neurosci Biobehav Rev 34:835-844

Sullivan RM, Raineki C, Barr GA (2011) Enduring effects of infant attachment induced by odor-shock conditioning: adult depressive-like behaviors and amygdala gene expression normalized by infant odor. Soc Neurosci Abstr 37:614.11.

Sullivan RM, Landers M, Yeaman B, Wilson DA (2000) Good memories of bad events in infancy. Nature 407:38-39.

Teicher MH, Andersen SL, Polcari A, Anderson CM, Navalta CP (2002) Developmental neurobiology of childhood and trauma. Psychiatr Clin North Am 25:397-426.
Teicher MH, Andersen SL, Polcari A, Anderson CM, Navalta CP, Kim DM (2003) The neurobiological consequences of early stress and childhood maltreatment. Neurosci Biobehav Rev 27:33-44.

Tyler K, Moriceau S, Sullivan RM, Greenwood-van Meerveld B (2007) Long-term colonic hypersensitivity in adult rats induced by neonatal unpredictable vs predictable shock. Neurogastroenterol Motil 19: 761-768.

Zahn-Waxler C, Shirtcliff EA, Marceau K (2008) Disorders of childhood and adolescence: gender and psychopathology. Annu Rev Clin Psychol 4:275-303.

Zeanah CH, Keyes A, Settles L (2003) Attachment relationships experiences and childhood psychopathology. Ann N Y Acad Sci 1008:22-30. 